\title{
Desobediência Civil na produção singular de cuidado em rede: outros olhares para a mãe usuária de drogas
}

Civil disobedience in the singular production of network care: other looks for the mother using drugs

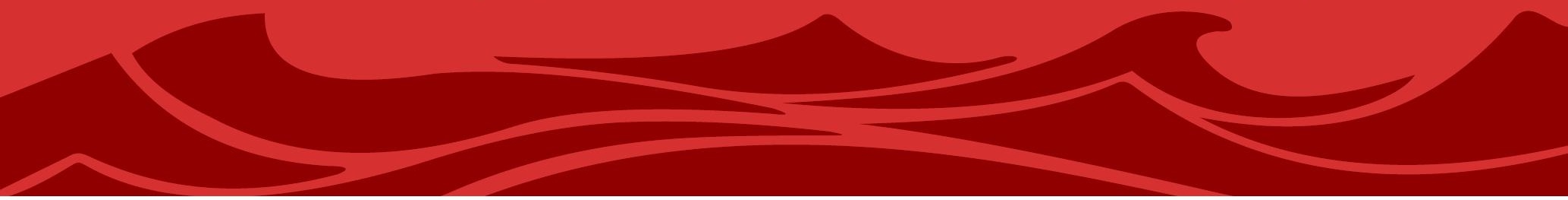

\section{Magda de Souza Chagas}

Professora Adjunta do Instituto de Saúde Coletiva da Universidade Federal Fluminense.

E-mail:magdaschagas@gmail.com.br

\section{Ana Lúcia Abrahão}

Professora Titular da Universidade Federal Fluminense

E-mail:abrahaoana@gmail.com.br

\section{Resumo}

Este texto integra parte dos resultados de uma pesquisa qualitativa de caráter multicêntrico realizada entre os anos de 2014 e 2016 no Brasil sobre redes temáticas do Sistema Único de Saúde. Neste material, trabalhamos com um caso de "desobediência civil" e a construção de rede de cuidado para uma jovem mãe de 24 anos de idade, usuária de drogas e que por este motivo perderia a guarda da filha recémnascida após o parto, não fosse a intervenção de alguns profissionais que conseguiram construir com e para mãe possibilidades no enfrentamento às drogas e sustentação da vida. A partir de narrativa construída junto com profissionais da atenção básica, foi possível acessarmos a complexidade da elaboração e manutenção do cuidado singular, principalmente em situações de vulnerabilidade, que pede amplas articulações, pactuações intersetoriais, acompanhamento e construção de estratégias para quem decide enfrentar e/ou interromper o uso de drogas na cotidianidade da vida diária. Por fim, destacamos a imensa relevância do olhar atento dos profissionais que apostam que toda a vida vale a pena e do quanto uma "aposta" no fortalecimento do vínculo afetivo mãe-filha no caso de usuárias de drogas grávidas pode impactar e produzir novos territórios existenciais, na reorganização das relações familiares e na autonomia da pessoa.

Palavras-chave: Narrativa; Atenção primária em saúde; Usuários de drogas; Gravidez de alto risco; Rede de cuidados continuados em saúde. 


\begin{abstract}
This text integrates part of the results of a qualitative research of multicenter character carried out between the years 2014 and 2016 in Brazil on thematic networks of the Unified Health System. In this material, we work with a case of "civil disobedience" and the construction of a network of care for a young 24-year-old female drug user and for this reason would lose custody of the newborn child after delivery, weren't for the intervention of some professionals who were able to build with and for mother possibilities in facing drugs and life support. Based on a narrative built together with primary care professionals, it was possible to access the complexity of the
\end{abstract}

\section{Introdução}

Nas últimas décadas o campo das políticas púbicas tem criado inúmeras articulações no enfrentamento ao uso do álcool, crack e outras drogas. Enfrentamento que ao ser assumido na dimensão de fenômeno social, exige a construção e atualização de abordagens para além da abstinência, como é o caso da inclusão da família no processo de tratamento/ reabilitação, ou mesmo da redução de danos. No entanto, ainda engatinhamos em aspectos que compõe este território, como a dimensão de gênero que ainda tem sido negligenciada.

O Relatório Mundial de Drogas da UNODC de $2017^{1}$ aponta que quando comparado o uso geral de drogas entre homens e mulheres, os homens são 3(três) vezes mais propensos a usar maconha, cocaína e anfetaminas do que as mulheres, que ainda apresentam uso mais baixo. No entanto, o consumo entre as mulheres tem aumentado nas últimas décadas elaboration and maintenance of singular care, especially in situations of vulnerability, which calls for broad articulations, intersectoral agreements, follow-up, and strategies for those who decide to face and/or stop the use of drugs in everyday life. Finally, we highlight the immense relevance of the attentive gaze of professionals who bet that all life is worthwhile and how much a "bet" in strengthening the mother-daughter affective bond in the case of pregnant drug users can impact and produce new existential territories, in the reorganization of family relations and in the autonomy of the person.

Keywords: Narrative; Primary health care; Drug users; Pregnancy high-risk; Delivery of health care.

e, embora elas sejam mais propensas a abusar de medicamentos prescritos por receita médica (opióides e tranquilizantes), quando iniciam o uso de outras drogas as mulheres podem avançar mais rapidamente que os homens no desenvolvimento de distúrbios no consumo de álcool, maconha e cocaína ${ }^{1}$. Isso tem sido comprovado no cenário epidemiológico brasileiro, em que tem aumentado o consumo de cocaína tanto na forma de pó ou nas formas impuras (crack e merla) por mulheres.

Em 2013 a estimativa era de que no Brasil havia 370 mil usuários de crack e destes $21,3 \%$ eram mulheres, solteiras (54\%), com média de 29 anos, cor não branca (78\%), baixa escolaridade ( $80 \%$ ensino fundamental) e com mais alta proporção de troca de sexo por drogas (55\%). Vale ressaltar que, diferente das mulheres, o item troca de sexo por drogas esteve presente apenas em $14 \%$ dos homens entrevistados. ${ }^{2}$ 
O crescimento do uso de drogas por mulheres exige a inclusão de outras ofertas de cuidado para além das abordagens convencionais, uma vez que está comprovada a forte associação do uso de drogas por este segmento com o aumento do número de filhos, a presença da gravidez durante processo de uso, não realização de pré-natal, maior número de complicações obstétricas e resistência de informar uso de drogas no momento do parto. Outras associações relevantes também estão presentes, como: baixa escolaridade, baixa renda, pobreza, abandono ou fragmentação familiar. $^{3,4}$

As mulheres trouxeram mudanças na cultura do uso das drogas, principalmente em relação ao comportamento sexual. A falta de condições financeiras pode levá-las a participar de atividades ilícitas e à prática sexual sem proteção em troca de drogas ou dinheiro, tornando-as sujeitas ao risco de gravidez indesejada e de doenças sexualmente transmissíveis. ${ }^{3: 55}$

Mulheres usuárias de drogas não configuram e m si um grupo homogêneo e a heterogeneidade dos sujeitos, as especificidades individuais e dos grupos em seus distintos contextos devem ser incorporadas no enfrentamento da questão. ${ }^{4}$

No entanto, se a prática do acolhimento ao usuário de drogas ainda não está livre de preconceitos por parte dos profissionais, isso não é diferente com a mulher e menos ainda com a gestante usuária de drogas, uma vez que a conduta é considerada incompatível com o que a sociedade e a cultura estabeleceu como papel feminino e mais ainda em relação à maternidade. Oliveira considera que "a incompatibilidade sociocultural atribuída à concomitância da maternidade e do uso problemático de drogas acarreta vulnerabilidades para as mulheres". 5:19 A situação ganha contornos mais sensíveis e problemáticos, uma vez que o uso de drogas pode interferir na saúde sexual, na saúde reprodutiva e agravar condições adversas com relação a morbimortalidade materno-fetal e infantil já que a mulher estará mais exposta a situação de violência sexual ou mesmo sexo como moeda de troca na obtenção da droga. ${ }^{2}$

Com o argumento de que o aumento do número de gravidez e o aumento do número de filhos de usuárias de drogas apresentava como consequência o abandono ou maus tratos aos recém-nascidos, em algumas capitais do Brasil como Rio de Janeiro, São Paulo e Belo Horizonte a justiça, em interpretação do Estatuto da Criança e Adolescente (ECA) e com vistas à "proteção da criança", através dos Conselhos Tutelares e das a Varas da Infância e Adolescência, "normatizou" que todas as gestantes que dessem entrada nas maternidades com informação de uso de drogas ou se a mãe recebesse "diagnóstico" por parte dos profissionais da instituição de saúde de ser usuária de drogas, passaria a ser considerada inapta e perderia imediatamente a guarda do recém-nascido(a) que poderia ser recolhido para abrigamento e colocado para adoção, ou algum membro da família (geralmente avós) passaria a ter a guarda da criança. A normativa da justiça, que não ganhou 
aspecto de lei ou decreto, precisava contar com a participação dos profissionais das instituições de saúde e a tensão provocada é possível ser vista em inúmeras reportagens em diferentes canais de mídia. ${ }^{6-13}$

Neste artigo, o objetivo consiste em trabalhar com um caso de desobediência civil, conceito apresentado pelo inglês Henry Thoreau em ensaio escrito em 1849, ao abordar a desobediência a um governo estabelecido e questionar o papel de cada um no uso da sua consciência e busca pelo justo e certo.

\begin{abstract}
Mas um governo no qual prevalece o mando da maioria em todas as questões não pode ser baseado na justiça, mesmo nos limites da avaliação dos homens. Não será possível um governo em que a maioria não decida virtualmente o que é certo ou errado? No qual a maioria decida apenas aquelas questões às quais seja aplicável a norma da conveniência? Deve o cidadão desistir da sua consciência, mesmo por um único instante ou em última instância, e se dobrar ao legislador? Por que então estará cada homem dotado de uma consciência? Na minha opinião devemos ser em primeiro lugar homens, $\mathrm{e}$ só então súditos. Não é desejável cultivar o respeito às leis no mesmo nível do respeito aos direitos. A única obrigação que tenho direito de assumir é fazer a qualquer momento aquilo que julgo certo. (...) A lei nunca fez os homens sequer um pouco mais justos; e o respeito reverente pela lei tem levado até mesmo os bem-intencionados a agir quotidianamente como mensageiros da justiça. ${ }^{14: 6}$
\end{abstract}

Este artigo toma o conceito de "desobediência civil" com vistas a construção de uma rede de cuidado para uma jovem mãe de 24 anos de idade, usuária de drogas e que por este motivo perderia a guarda da sua filha recém-nascida após o parto. A história foi construída a partir de narrativas de profissionais da atenção básica que acompanharam a mesma nos serviços da atenção básica e hospitalar. Uma vida que vive no limite da fragilidade e vulnerabilidade, que convoca os sentimentos mais distintos dos profissionais que precisam reinventar formas de produzir cuidado na precariedade, na dinâmica volátil das necessidades cotidianas. Lidar com julgamentos morais e com sofrimentos diante da incapacidade de resolver alguns problemas aparentemente banais, revelam o limite da clínica biomédica e exige a construção de redes fora da formalidade e do comum de um atendimento pré-natal. A dificuldade diante da necessidade de desenvolver políticas intersetoriais está presente em situações que frequentemente falamos, defendemos, discutimos, mas que pedem constantes atualizações, realizações na vida e no fazer cotidiano das equipes de saúde.

\section{A base e o cenário da narrativa}

Entre os anos de 2014 e 2016 foi realizada a pesquisa Observatório Nacional de Produção de Cuidados em diferentes modalidades à luz do processo de implantação das redes temáticas de atenção à saúde no Sistema Único de Saúde: avalia quem pede, quem faz e quem usa. Financiada pelo Ministério da Saúde e aprovada no Comitê de Ética e Pesquisa (CEP) sob o número do parecer: 876.385 , em 18/11/2014.

De caráter multicêntrico a pesquisa pôde contar com diferentes frentes de pesquisa em 04 (quatro) regiões do país: Norte, Nordeste, 
Sudeste e Sul. Assim como, foi desenvolvida em parceria com os diferentes atores que conhecem, vivenciam e compõem a trama do cuidado: usuários, profissionais e gestores.

O objetivo da pesquisa estava em realizarmos aproximações às equipes de saúde dos diferentes pontos de rede e a partir do acompanhamento da atuação cotidiana de cada equipe perceber a construção ou não de rede de cuidados. Ou seja, como uma proposta macropolítica como é a Rede Cegonha, ganha corporeidade no dia a dia entre profissionais de saúde e usuários do serviço? Os profissionais conseguiam executar na prática o que estava previsto na portaria ou viviam dificuldades? Quais eram as dificuldades e como enfrentam as mesmas? Assim, vivenciar os territórios e acompanhar a dinâmica diária dos serviços com algumas equipes, nos apresentou tensões e experimentações para além do que poderíamos esperar em relação à rede de atenção à saúde. Situações complexas e articulações intersetoriais ganharam visibilidade, como no caso entre a saúde, a justiça e a perda da guarda por parte das mães usuárias de drogas que davam entrada nas maternidades do Rio de Janeiro no período da pesquisa.

Neste texto, o cenário de acompanhamento dos profissionais, usuários e gestores foi a Atenção Básica, um dos níveis do sistema de saúde que tem passado por mudanças significativas nos últimos anos no país e que provocam enfrentamentos e tensões entre modelos de atenção, a construção de novas relações entre profissionais da saúde e usuários, assim como a incorporação e discussão de território para além do território físico ${ }^{15}$ com experimentações e produções do cuidado nos territórios existenciais, ${ }^{16,17}$ tem trazido muitas discussões sobre a forma de cuidar na Atenção Básica. Ou seja, reconhecer que no acompanhamento dos usuários estamos em contato com os diferentes territórios percorridos e construídos na dinâmica de produção de saúde.

O processo de construção de vínculo e responsabilização do cuidado com usuários, um dos dispositivos da atenção básica, ganha dimensão diferenciada e questiona positivamente os resultados alcançados que são medidos por indicadores previamente pactuados. No entanto, já não é suficiente apostar somente nas regras, nas evidências ou algoritmos de atendimentos diante de usuários que não aderem aos tratamentos propostos, ou resistem às ofertas mesmo vivendo situação de fragilidade e/ou vulnerabilidade. Estes usuários que poderiam ser (e são para muitos) considerados à margem, ou dispensados com facilidade dos serviços de saúde, exigem dos profissionais/trabalhadores e gestores reinvenções constantes na aproximação, no vínculo e na construção da oferta de cuidado, pois o pedido de ajuda pode ser simplesmente comparecer ao atendimento.

Durante 09 (nove) meses do ano de 2015 acompanhamos regularmente as reuniões de 
uma equipe da atenção básica na cidade do Rio de Janeiro. A observação participante e o uso de diário de campo foram fundamentais. Nas reuniões, os casos que poderiam ser denominados complexos dominavam completamente a pauta, não apenas pela necessidade de aprofundamento das questões para tomada de decisões que ocorriam em discussões interdisciplinares, mas como situações em que a equipe constantemente estava convocada a produzir novos territórios, reinventar ferramentas, manejos e articulações para fora e dentro da unidade, para sustentar a leveza da vida.

A partir do recolhimento das reuniões com a equipe, diário de campo, e as anotações da observação participante, construímos a narrativa sobre "Chego com a Tarde", denominação para uma das pessoas acompanhadas pela equipe a qual nos vinculamos. A Narrativa sobre "Chego com a Tarde" destaca a vivência dos encontros com a equipe pois, delineia e revela os arranjos e modos de cuidar, e suas estranhezas ressoam alto na construção das redes de cuidado que são operacionalizadas no movimento de suportar a fragilidade da vida.

Adotamos a narrativa como estratégia na apresentação dos resultados, inspiradas tanto em Benjamin (1989) que discute sobre a importância da escrita e destaca ser necessário que "guarde distância de qualquer teoria, que deixe falar a criatura, que cause estranheza e ressoe alto", 18:3 como em Barthes para quem:
A narrativa é uma prática da linguagem vinculada a um acontecimento articulado a memória, desencadeia efeitos ativos por incluir elementos como o contato, nesse sentido opera como dispositivo favorável a experiência singular. Sua função não é de representar, é de construir um espetáculo ainda que permaneça no enigmático. [...] é possível que os homens reinjetem sem cessar na narrativa o que conheceram, o que viveram; ao menos isto está em uma forma que ela, triunfou da repetição e instituiu o modelo de um vir a ser $[\ldots]^{19: 60}$

\section{A Narrativa sobre-Chego com a Tarde}

Chego com a tarde tem 24 anos, mora desde que nasceu no território em que a equipe é responsável. A mãe cometeu suicídio quando ela tinha 2 anos de idade, quando então foi morar com a avó e a tia. Entre 9 e 11 anos foi abusada sexualmente por um vizinho e familiar. Passou a usar drogas na adolescência e no curso do uso da droga continuou a sofrer violência sexual. Assim, foi abusada a partir da infância e passou porabuso até a idade adulta.

Ela saia para usar drogas e depois retornava à equipe da Estratégia de Saúde da Família (ESF) com as questões relativas ao abuso de drogas e violência sexual. Foi internada 02(duas) vezes para reabilitação do uso de drogas, saiu da internação, mas sempre manteve a questão do abuso com constantes repetições. No ano passado (2014) procurou o "posto" para atendimento com história de nódulo na mamae dor local. Ela tinha forte vínculo com a Agente Comunitária de Saúde (ACS), que mesmo de licença médica acompanhou Chego com a Tarde para a consulta. Logo depois da terceira vez que veio a ESF, foi pedido teste e confirmada a 
situação de gravidez, sendo então encaminhada para acompanhamento de gestação de alto-risco em maternidade de referência, mas dificilmente ela comparecia as consultas fosse na maternidade ou na ESF.

Foi então que, assim como em outros casos de alta vulnerabilidade, a equipe passou a atendêla na hora que ela vinha. Ela tinha o telefone da enfermeira e ligava muito para ela, elas ligavam uma para outra e o vínculo ficou cada vez mais forte. O vínculo com a ACS, a médica e a enfermeira da equipe era forte, mas mais expressivo com a enfermeira que quando tinha uma brecha de horário "livre" ligava e pedia para Chego com a Tarde ir à unidade. O prénatal dela foi assim, nas brechas de horários, com a ACS encontrando-a no meio da rua e levando-a para unidade, com os profissionais da equipe levando-a pelo braço, nas possibilidades e apostando no vínculo. Sempre comparecia à unidade após uso de drogas, muitas vezes virada, poucas vezes sem uso. No período em que descobriu que estava grávida a avó faleceu, o maior vínculo afetivo dela, e ela aumentou ainda mais uso da droga.

Depois de passar uma noite inteira na rua usando drogas, ela começou a sentir dor e foi para unidade (ESF), chamaram a ambulância e ela foi para a maternidade. Quando chegou na maternidade relatou o uso da droga porque tinha medo que a filha tivesse alguma sequela. A filha nasceu bem e após o parto ainda permaneceu por tempo mais prolongado na maternidade, isso porque as maternidades no
Rio de Janeiro estavam sobre a orientação de que diante de toda criança filha de usuária de drogas os profissionais, no caso a assistente social, deviam acionar o Conselho Tutelar e a Vara da Infância, a mãe perdia a guarda do recém-nascido e a maioria das crianças saiam da maternidade geralmente para um abrigo de acolhimento.

No entanto, aqui ocorreu a desobediência civil da assistente social da maternidade que recebeu Chego com a Tarde e que a acompanhou no pós-parto. Ao perceber a afetividade de Chego com a Tarde com a filha, a maneira cuidadosa de estar com a criança, os cuidados realizados e certa alegria, a assistente social optou pelo fortalecimento do vínculo da mãe com a filha, não acionou o Conselho Tutelar nem a Vara da infância e sim resolveu acionar a equipe de referência da ESF que acompanhava Chego com a Tarde para a construção de uma proposta conjunta de continuidade de cuidado de mãe e filha, tanto por parte da maternidade quanto pela ESF, um claro arranjo de rede de cuidado, envolvendo atenção básica e maternidade. Neste arranjo de rede formal e informal de cuidado, a família foi acionada e solicitado apoio das tias de Chego com a Tarde.

Quando no momento da alta da maternidade a transferência de cuidado foi realizada na ESF, onde os profissionais envolvidos se conheceram e a assistente social da maternidade entregou o relatório social e da psicologia sobre Chego com a Tarde aos 
profissionais da ESF. Houve então, o encontro e puderam conversar sobre algumas propostas de como sustentaro cuidado mãe e filha.

Chego com a Tarde voltou para casa de uma das tias (ela tem duas tias e uma prima, que são mais presentes) e mora agora com esta tia, o marido e a filha do casal. Desde de que saiu da maternidade, passados 07(sete) meses, Chego com a Tarde relatou que não tinha mais usado cocaína, que era o que ela usava com mais frequência, e nem crack, que usava esporadicamente. Durante as conversas com a equipe da ESF mencionava estar muito ansiosa em relação ao uso de drogas, falava que sonhava, falava de fissura e que estava conseguindo segurar e tinha usado maconha.

Uma das questões que a equipe passou a vivenciar diariamente e criar situações de manejo, foi justamente quando da alta do acompanhamento da psiquiatria da maternidade. A equipe começou a construir estratégias para sustentar o cuidado com Chego com a Tarde, como o atendimento semanal na unidade. $O$ vínculo com a equipe, facilitou inclusive a extensão do contato com a equipe do Núcleo de Atenção Saúde da Família (NASF), mas não era suficiente pois a ansiedade de Chego com a Tarde era percebida por cada membro da equipe e a própria relatava fissura e sonhos. Por este motivo consideravam que seria importante ocupar o dia de Chego com a Tarde com atividades. No primeiro momento passaram a convidá-la simplesmente para ir para a unidade e diante da insuficiência de atividades, passaram a construir agenda de cuidados para que ela sempre estivesse na companhia de alguém fosse da ESF ou do NASF, para que não só ocupassem o tempo dela, mas que apresentassem alguma oferta diferenciada para ela e a filha. Articulado a isso pediram apoio ao Centro de Atendimento PsicoSocial (CAPS) porque entendiam que era importante, ela estar em um espaço terapêutico fora de casa e da unidade, uma vez que quando não ia para a unidade, ficava o dia inteiro em casa e só podia sair com uma das tias.

A preocupação de Chego com a Tarde estava no fato de que para ela comparecer à unidade alguém teria que acompanhá-la e este alguém era a tia e elas estavam brigando muito. O não sair sozinha era por insegurança pois tinha que passar por lugares de uso de drogas. Assim, a equipe considerou que era importante que ela tivesse em algum outro espaço durante o dia. Foi então que a equipe se deparou com a dificuldade de não ter oferta de unidade de apoio, muito menos de unidade de apoio que pudesse levar ou deixar a criança enquanto Chego com a Tarde estivesse em atividade. Também não conseguiam dar fluxo aos desejos de Chego com a Tarde de fazer um curso de massagem, pois já tinha trabalhado com massagem, ou trabalhar como técnica de informática (curso que ela fez), com cuidado de idosos...

Diante das constantes brigas entre a tia e Chego com a Tarde a equipe resolveu convidar a tia para uma conversa e esta apresentou como questão para as brigas constantes, o fato de 
que Chego com a Tarde iniciará um relacionamento com uma mulher e esta, estava indo muitas vezes em casa da tia, para visitar Chego com a Tarde e a bebê. Este fato preocupava a tia, pois a mesma entendia que poderia ser risco para Chego com a Tarde, e a filha e que por isso desde então elas (tia $e$ sobrinha) passaram a brigar muito. $O$ relato $d a$ tia reposicionou a equipe que agendou uma reunião na unidade com toda a família para tratar da questão. A abordagem seguiria a intenção de evitar situação da família de vinalizar a companheira de Chego com a Tarde. Os ciúmes da tia e o fato de que a companheira estava assumindo o papel de pai da bebê, eram temas discordantes entre tia e sobrinha. A equipe, considerava fundamental o exercício de não julgamento moral e de que era importante buscar entenderas partes.

Naquele período o Conselho Tutelar realizou algumas visitas a Chego com a Tarde e percebeu que tanto a mãe quanto criança estavam bem. A ACS relatou que participou da visita com a conselheira e confirmou que a bebê estava ajudando na recuperação de Chego com a Tarde, que mesmo com mastite continuou a amamentar a filha e a única reclamação foi de dor, mas que ela não parou de amamentar, além disso, continuou a ACS, era possível ver Chego com a Tarde que estava rindo, brincando e do quanto ela falava sobre a filha.

Além do acompanhamento do Conselho Tutelar, algo que chamou muita atenção da equipe, de forma pouco positiva, foi o fato de terem que responder a relatório/questionário encaminhado pelo conselho onde deveriam informar a situação de saúde geral de Chego com a Tarde incluindo a situação mental. Os detalhes cobertos pelo questionário provocaram intensa discussão na equipe pois todas, sem exceção, consideraram que se tivessem que responder, eles próprias, às questões apresentadas no formulário, perderiam a guarda de seus próprios filhos.

\section{O que Chego com a tarde traz para a conversa?}

A ideia de que a vida de qualquer pessoa vale a pena deve ser levada ao máximo efeito em situação de vulnerabilidade e fragilidade e assim precisa de rede de cuidado diferenciada. Esta rede não deve ser entendida apenas como a rede de serviços, que precisamos fortalecer e articular para que seja resolutiva, mas deve incluir a vida do usuário, suas dores e amores, suas próprias redes de proteção familiar, de amigos, de bairro, seus territórios existenciais e assim a existência em redes vivas.

Existe uma aposta na vida e mesmo diante de inúmeras dificuldades e situações que colocavam em questão o agir de cada membro da equipe não foi percebido movimento de fuga para evitar encontros, o mergulho que os profissionais fazem é intenso na relação com alguns usuários. No entanto, chama atenção que os trabalhadores da saúde estão sem proteção, sem apoio, sem rede de cuidados que abra reflexão sobre os afetos alegres e tristes que experimentam. 
A desobediência civil passou pelo exercício do direito dos profissionais em assumir e fazer, neste caso, aquilo que julgaram ser o correto, para mãe e a criança. Em um claro uso de uma consciência que busca pelo justo e certo em defesa de qualquer vida vale a pena.

A escolha da história de Chego com a Tarde ocorreu por similaridades com outro caso que a equipe acabara de vivenciar com desfecho fatal (morte) e que tinha deixado marcas "traumáticas" em todos, pois tinha ocorrido perda de guarda da filha recém-nascida. A equipe deixou claro que "este" era apenas mais um caso no meio de tantos com enredo semelhante. Este caso, assim como outros, atravessava os limites da atenção básica habitualmente conhecidos, nele mais de uma rede de cuidado se entrecruzava (cegonha, crack e justiça), colocava em evidência e "em xeque" a responsabilização da equipe inclusive na garantia da continuidade do cuidado em outro equipamento da saúde e a articulação em rede da atenção básica e a rede hospitalar.

A situação em questão expõe o quanto a Rede Cegonha definida na portaria é insuficiente e não dá conta do mundo da vida e usuárias e trabalhadores da saúde criam novas redes e arranjos para o cuidado. Protocolos, normas e leis precisam de atualização constante e repactuação das questões, principalmente as relacionadas a intersetorialidade, como no caso do código civil, a perda da guarda e as apostas na vida de qualquer pessoa. A Rede Cegonha, ou mesmo o programa Cegonha Carioca, não colocam na pauta a situação que esta equipe experimentou, como tantas outras no país. Ou seja, o que fazemos quando as redes de cuidado se cruzam na pessoa? Uma gestante como esta exige cuidados singulares, escuta cuidadora, tempo e encontros individualizados com ofertas que sustentem, junto com a equipe 0 cuidado também fora do estabelecimento de saúde. Sustentar a relação mãe criança, em franca desobediência aos protocolos da justiça, foi um trabalho vivo em ato, sustentado por uma rede viva construída no cruzamento de que toda vida vale a pena.

Foi (ainda é) significativa a aposta na vida de Chego com a tarde, a começar pela observação singular da assistente social que defendeu a permanência da bebê com a mãe e assim também apostou na vida e cuidado com Chego com a tarde. Naquele momento em que "desobedeceu" as "normas" e olhou para a vida aquela trabalhadora da saúde se experimentou e convidou tantos outros a experimentarem outras construções sob a égide do Efeito Pororoca $^{20}$, onde os trabalhadores se deixam afetar pelas relações e saberes, recebendo de volta, como aprendizagem, o agir e o saber do outro. Assim como operaram com o que defende Merhy:

\footnotetext{
(...)o SUS só se realiza na medida que se governa pelo lema: a vida de qualquer um vale a pena. E se a vida de qualquer um vale a pena, isso deve ter a força, tensa é verdade, de que ali no fazer cotidiano do cuidado, não é só a vida de quem se considera como socialmente significante que deve ser valorada, mas de modo fundamental a vida daquele morador de rua, daquele desinvestido socialmente. ${ }^{21: 35}$ (grifo das autoras)
} 
Existe trabalho realizado para além da rede estabelecida nas portarias, existe construção de rede viva, ${ }^{22}$ de rede de afetos e cuidado, sendo ou não coordenada pela saúde, mas que pode e deve ser incorporada pelas equipes. Como neste caso em que foi construída uma rede articulada com a instituição de atendimento à gestação, construção de rede de desejos de ser (questões profissionais e de descobertas como habilidade para massagem) e possibilidades na relação direta com gestante (depois puérpera) na busca de entender, ofertar e participar do processo de "recuperação" dela, articulação e construção constante junto ao Conselho Tutelar na garantia da permanência da guarda e ainda ampla rede de afeto e cuidado envolvendo profissionais da equipe mais o NASF (Núcleo de Apoio à Saúde da Família) e deixando-se envolver com/na relação família.

A intensidade dos acontecimentos que esta equipe vivenciou e tem vivido não é algo que se sustente com habilidade clínica, ou manejo terapêutico, há necessidade de um olhar cuidadoso, para isso é urgente e necessário oferecer suporte para outras experiências que continuem sendo motor para produção de subjetividade. O cuidado construído com/para cada um que apresenta extrema fragilidade na condução da vida (gestantes, adolescentes, usuários da saúde mental, idosos encarcerados) toda a complexidade que envolve todos os casos... A equipe realiza enfrentamento no trágico, sem fuga. $O$ que não deixa de afetar os corpos de cada trabalhador!
Podemos tomar aqui o Efeito Sanfona/Efeito Bandoneón ${ }^{23}$ ao olhar a relação dos profissionais com os usuários e produzir assim um cuidar de si. Um aproximar-se e afastar-se, um vai e vem, certa elasticidade diante da delicadeza necessária. Em situações que pedem a profundidade da pele nos colocamos em possibilidade de experimentar e conhecer tanto o outro quanto a nós mesmo. No entanto, não é possível ficar o tempo todo aberto e nem o tempo todo fechado. Se assim for não se produz música e há risco de perder o instrumento, a potência, a vibração, a afinação. Um instrumento fechado ou com pouca abertura não se experimenta nas tantas possibilidades musicais, nas tantas possibilidades na vida.

A proximidade e relação "in-munda" da equipe de saúde, ${ }^{24}$ principalmente com os usuários em situação de fragilidade e/ou vulnerabilidade, impunha questionamentos e reposicionamentos dos membros da equipe, como foi o caso da discussão de redução de danos para Chego com a tarde quando foi citado o uso da maconha no lugar do crack; ou o envolvimento dos trabalhadores da saúde em questões para além do que comumente poderíamos denominar estar na competência deles, como a equipe chamar a família para conversar e contextualizar a possível bissexualidade de Chego com a tarde. Se existe a macropolítica, se existe a micropolítica, brincamos aqui, com a ideia de que a equipe está lidando com a nanopolítica. Mergulhos intensos pedem respiros. Como cuidar da equipe e estas de cada um? 


\section{Referências}

${ }^{1}$ United Nations Office on Drugs and Crime. World drug report; 2017. United Nations publication; 2017.

${ }^{2}$ Ministério da Saúde (BR), Fundação Oswaldo Cruz. Pesquisa Nacional sobre o uso de crack: quem são os usuários de crack e/ou similares do Brasil? Quantos são nas capitais brasileiras? [Internet] Rio de Janeiro: Editora ICICT/FIOCRUZ, 2014. [citado 2 nov 2017] Disponível em: https://www.icict.fiocruz.br/sites/www.icict.fiocruz.br/files/Pesquisa \%20Nacional\% 20sobre\%200\%20Uso\%20de\%20Crack.pdf.

${ }^{3}$ Marangoni SR, Oliveira MLF. Uso de crack por multípara em vulnerabilidade social: história de vida. Ciência Cuidado Saúde. 2012 Jan/Mar; 11(1):166-172.

${ }^{4}$ Medeiros KT, Maciel SC, Sousa PF, Vieira GS. Vivências e Representações sobre o Crack: Um Estudo com Mulheres Usuárias. Psico-USF. 2015; 20(3):517-528.

${ }^{5}$ Oliveira DS. Vivências e enfrentamentos de mulheres que usam drogas no exercício da maternidade. [Dissertação de mestrado] Universidade Federal da Bahia, Escola de Enfermagem, Programa de Pós-Graduação em Enfermagem, 2015.

${ }^{6}$ Me obrigaram a entregar o meu filho', diz mãe ativista de BH. Estado de Minas. [citado em 5 nov 2017] Disponível em: https://www.em.com.br/app/noticia/gerais/2017/10/15/interna_gerais,908649/me-obrigaram-a-entregar-o-meufilho-diz-mae-ativista-de-bh.shtml

'Justiça afasta filhos de mães dependentes. O Tempo. [citado 5 nov 2017]. Disponível em: http://www.otempo.com.br/ cidades/justi\%C3\%A7a-afasta-filhos-de-m\%C3\%A3es-dependentes-1.1467710.

${ }^{8}$ Uso distorcido da lei separa mães pobres e usuárias de crack dos filhos. Rede Brasil Atual. [citado 5 nov 2017]. Disponível em: http://www. Redebrasil atual.com.br/revis tas/131/uso-distorcido-da-lei-e-responsavel-por-separarmaes-pobres-e-usuarias-de-crack-dos-filhos.

${ }^{9}$ Mulheres e o crack. Revista Crescer. [citado 5 nov 2017]. 2015. Disponível em: http://revistacrescer.globo.com/Gravidez/ Saude/noticia/2015/02/mulheres-e-o-crack.html

${ }^{10}$ Bebês abandonados por adolescentes viciadas em crack preocupa autoridades do Rio. Empresa Brasileira de Comunicação [citado 5 nov 2017]. Disponível em: http://www.ebc.com.br/noticias/brasil/2013/09/bebes-abandonadospor-adolescente s-viciadas-em-crack-preocupa-autoridades-do

${ }^{11}$ Lar para filhos do crack. [citado 5 nov 2017]. O Dia. 13 maio 2013. Disponível em: http://odia.ig.com.br/noticia/rio/201305-13/lar-para-filhos-do-crack.html

${ }^{12}$ Grávidas do crack. Folha de São Paulo [citado 5 nov 2017]. Disponível em: http://www1.folha.uol.com.br/fsp/cotidiano/ 19638-gravidas-do-crack.shtml

${ }^{13}$ Os órfãos do crack. A Gazeta. [citado 5 nov 2017] Disponível em: http://gazetaonline.globo.com/_conteudo/2010/11/ 701280-os+orfaos+do+crack.html

${ }^{14}$ Thoreau HD. Desobediência Civil. [Internet] Ebooks Brasil; 2001. [citado 9 nov 2017]. Disponível em: http://www.ebooks brasil.org/adobeebook/desobedienciacivil.pdf

${ }^{15}$ Ministério da Saúde (BR). Política Nacional de Atenção Básica. Brasília: Ministério da Saúde, 2012. (Série E. Legislação em Saúde).

${ }^{16}$ Guattari F. As três ecologias. 7.ed. São Paulo: Editora Papirus, 2001.

${ }^{17}$ Ramoa, ML, Alarcon S, Lancetti A, Petuco D, Pekelman R. Território, território existencial e cartografia. In: Ministério da Saúde (BR), Fundação Oswaldo Cruz, Grupo Hospitalar Conceição. (Org.). Caminhos do Cuidado: caderno do aluno. 1.ed. Brasília: Ministério da Saúde, 2013. p. 71-74.

${ }^{18}$ Benjamin W. Diário de Moscou. São Paulo: Companhia das Letras; 1989.

${ }^{19}$ Barthes R. A aventura semiológica. São Paulo: Martins Fontes; 2001.

${ }^{20}$ Silva ALA. Produção de subjetividade e gestão em saúde: cartografias da gerência. [Tese de doutorado] Campinas: Universidade Estadual de Campinas; 2004.

${ }^{21}$ Merhy EE. Saúde e Direitos: tensões de um SUS em disputa, molecularidades. Saúde e Sociedade. 2012;21(2):267-279.

${ }^{22}$ Merhy EE, Gomes MPC, Silva E, Lima MF, Cruz KT, Franco TB. Redes Vivas: multiplicidades girando as existências, sinais da rua. Implicação para a produção do cuidado e a produção do conhecimento em saúde. Divulgação Saúde debate, Rio de Janeiro. 2014;(52):153-164. 
${ }^{23}$ Chagas MS. Chamei a morte para a roda ela quis danças ciranda, mudança: estudo descritivo sobre o processo de cuidar diante da finitude. [Tese de doutorado] Rio de Janeiro: Universidade Federal do Rio de Janeiro; 2016.

${ }^{24}$ Abrahão AL, Merhy EE, Gomes MPC, Tallemberg C, Chagas MS, Rocha M, Santos NLP, Silva E, Vianna L. O pesquisador IN-MUNDO e o processo de produção de outras formas de investigação em saúde. In: Gomes MPC, Merhy EE (Org.). Pesquisadores IN-MUNDO: um estudo da produção do acesso e barreira em saúde mental. 1.ed. Porto Alegre: REDE UNIDA; 2014. v. 1, p. 155-170. 